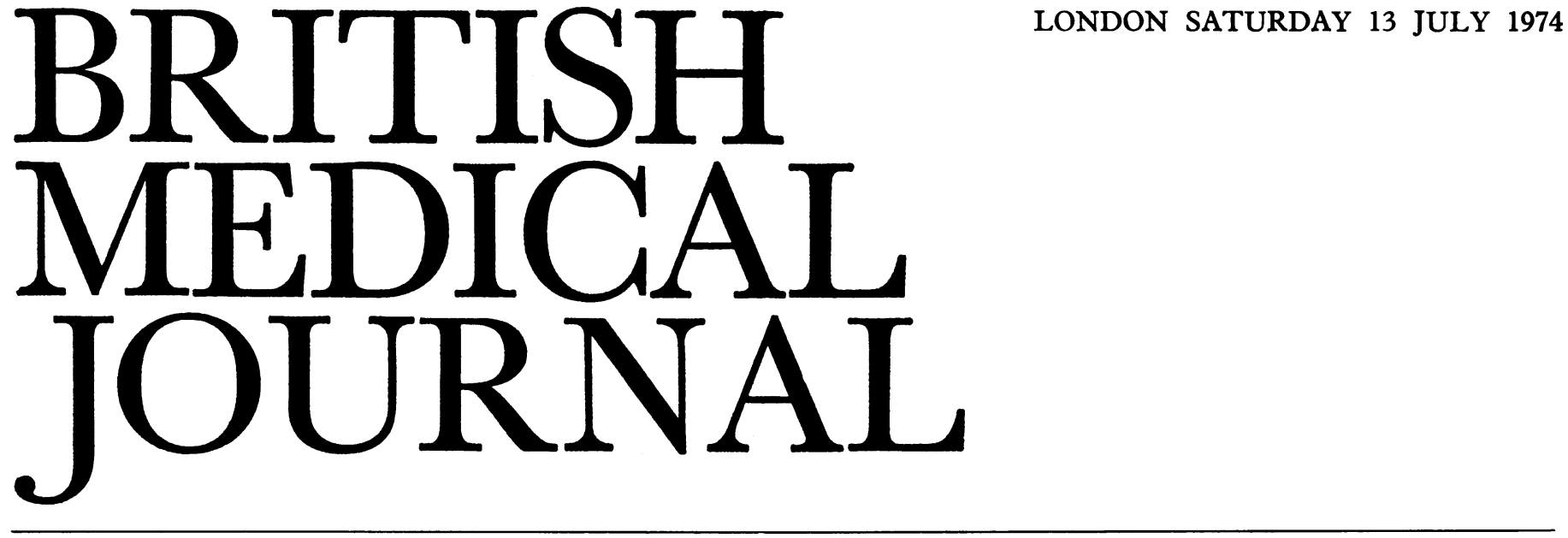

\title{
Private Practice and the N.H.S.
}

The conflict last week at Charing Cross Hospital about private patients would never have arisen had not those concerned had their patience stretched to breaking point. The porters, orderlies, and other ancillary workers who make up the bulk of members of the hospital branch of the National Union of Public Employees have been paid far too little for far too long, and doctors might well ask themselves what if anything they have done about it. Having said all that, however, the union's action in seeking to force private patients out of N.H.S. hospitals and its tacit support by the Secretary of State for Social Services (see pp. 124 and 127) were quite unjustifiable and represented a serious threat to the future of the Health Service. On this occasion, as it happened, hospital consultants were equally short of patience as a result of the financial crisis in the N.H.S. and the disappointing Review Body Report, so they acted resolutely. There can be no doubt that it was only the B.M.A.'s threat of sanctions that persuaded Mrs. Castle to intervene at the weekend to negotiate a settlement of the dispute. Her actions and words in the last few days have opened a wide gulf between her and the medical profession.

The reason that the union's actions were so disturbing is that for the first time a group of workers within the N.H.S. has set out to achieve a political change by industrial action.

Few would deny that workers have a legitimate claim to more participation in management decisions: but that is a very different matter from demanding a total change of policy and backing the demand with threats. Furthermore exclusion of private patients from an N.H.S. hospital was not a decision that its management could legitimately take, for the discretion to permit private patients is quite clearly vested in the Secretary of State. She is not legally bound to permit private practice within the N.H.S., but she is empowered to do so by the Health Services and Public Health Act 1968, and it would need legislation for that power to be denied to her successors. Furthermore for 26 years now it has been a convention that any change in facilities for private practice within the N.H.S. are made only after negotiation between the Department of Health and representatives of the medical profession. Mrs. Castle recognizes this. She took office in a Government whose policy proposals included the phasing out of private practice, yet she insisted on including private practice among the matters to be examined by the joint working party on consultants' terms and conditions of service-the Owen Working Party. ${ }^{1}$ If the decisions of that working party-and subsequent negotiations with the profession-can be pre-empted by the militant action of one union then the N.H.S. is well on the way to anarchy. An appropriate analogy could be made with certification. General practitioners recently agreed that doctors should negotiate an end by 1976 to their duty to issue National Insurance Certificates to patients. If the B.M.A. followed the example set by N.U.P.E. it would have announced that the decision had been made and there was no point wasting time waiting for negotiation.

Despite the Government's partial change of heart at the weekend, it seems that two fundamental features of an ordered society have been threatened by its behaviour. Firstly, unions should not be allowed to believe that they can force changes in policy affecting millions of citizens overnight by the strength of industrial action; and secondly the result of consultations should not be taken for granted, even by a Minister. For it is far from certain that a careful examination of the question of private medicine-even by those who are attracted by the concept of removing it from the N.H.S. - would lead to the conclusion that the two should indeed be separated. The compromise was introduced by Aneurin Bevan in 1948 for sound, practical reasons and it may be that even the present Government might recognize the force of these practical arguments if it thought about them rationally rather than emotionally.

In any democratic state some people will be willing to pay for the courtesies and conveniences of private treatment. (The fact that private patients do not have to wait two years for a hernia operation is evidence of the faults of the N.H.S. rather than of the evils of private practice.) Some people value their time highly enough to pay for the doctor to come to them rather than travel to his consulting room; others value their privacy, or wish to be able to continue their work while in hospital, or simply to exercise choice of doctor and have a guarantee of his personal attention. These reasons are good enough for politicians, though Conservatives tend to go to the King Edward VII Hospital for Officers while Socialists apparently prefer the Manor House Hospital in Golders Green-a hospital largely supported by the trade union movement. The reputation of British medicine is still high enough to attract many foreign patients here year by year, and their fees make a substantial contribution to the invisible earnings of the United Kingdom. The demand exists: and there will always be doctors prepared to satisfy that demand. Nor, of course, is this simply a small charmed circle of very rich patients and a few very rich doctors: the number of those covered by B.U.P.A., P.P.P., and other health insurance schemes has risen steadily in recent years and is now several million, while 
current estimates suggest that over half of all N.H.S. consultants do some private work.

Few thoughtful people would argue, then, that all private practice should be stopped. However, it is possible to present a rational argument that N.H.S. staff should not be allowed to charge fees to private patients. Many academic clinicians, for example, accept such a restriction. Doctors could be given the choice of working for the N.H.S. or in private practice, and the present part-time contract abolished. The consequences of such a decision are hard to predict. Certainly in the present climate of opinion it would cause profound resentment among hospital staff, many of whom would look for ways of leaving the N.H.S. or the country. Long-term it would surely result in a two-tier system, with one standard for the rich and another for the rest-as there is in education. No doubt, as in education, some of the private sector would be expensive and bad; but also as in education much of the public sector would be worn out, understaffed, and worse.

The present threat is not as extreme as that, however. Mrs. Castle and her left-wing supporters seem set on the exclusion of private practice from N.H.S. hospitals but they have not committed themselves about the option for a part-time contract for consultants.

In fact, of course, for many consultants the only reasonable place that they can treat private patients is in an N.H.S. hospital. Technological advances in medicine have been so rapid recently that for many disorders it is no longer possible to offer patients the best possible treatment in a nursing home or a private clinic. Only a fairly large modern hospital can provide the necessary laboratory facilities, $x$-ray equipment, recovery rooms, and intensive care units that are needed for good quality medical care. This can be provided in the private sector-and the Wellington Hospital opened earlier this year has set out to do so-but it is very expensive, and such units would not be economically viable in large numbers throughout the country unless there was a very big change in the organization of medical care. Certainly outside the major centres most doctors will prefer to admit their patients to a private bed in an N.H.S. hospital rather than to a nursing home if that choice is open to them.

Why should the N.H.S. offer these facilities? The reasons are practical ones, and were clearly explained ${ }^{2}$ by the Royal Commission on Medical Education in 1968. Providing facilities for private practice at a hospital avoids "the waste of time and effort involved in travelling to and from private consulting rooms and clinics elsewhere, and the need to maintain a separate office staff and to arrange for independent laboratory investigations." In London, for example, consultants can choose between rooms in or around Harley Street or in their own hospital; and the time saved by a "geographical full-time" practice is enormous.

Time-saving is not the only advantage: more important is the fact that the consultant can be contacted reliably and can come quickly should an emergency arise-either in his N.H.S. wards or in the private beds. Even at present he may well be unobtainable-perhaps with his car caught in a traffic jam. Such a situation will become more frequent if consultants are forced to find private clinics outside the hospitals where they spend most of their time.

What does the N.H.S. lose by the present arrangement? Radiographers, laboratory technicians, and other ancillary workers sometimes object to assisting in the management of private patients as part of their standard duties. The patient pays for their services, however; and the fees go not to the consultant but to the hospital. If costings are realistic-and they should be-then wards such as that at Charing Cross should be making a profit for the N.H.S.

The fundamental flaw in the case against private practice is the claim that it diverts resources from the public into the private sector. The converse is the case. At present a substantial proportion of hospital consultants' earnings comes from private practice. If the amount of private medicine were reduced more money would have to be found from taxation to restore these earnings to something close to their present levels; and in the same way the $x$-rays, laboratory investigations, and other procedures within the hospital service paid for by private patients would have to be paid for by the N.H.S. Waiting lists would grow longer-very few surgeons would do routine surgery at weekends as part of their N.H.S. contracts, yet most private patients are seen out of normal working hours. Already the economic advisers to the B.M.A. calculate that the N.H.S. needs another $£ 500$ million a year if it is not to collapse. Take away private practice and even that sum will prove too small.

1 British Medical fournal, 1974, 1, 532.

2 Royal Commission on Medical Education 1965-68, Report. Cmnd. 3569 London, H.M.S.O., 1968.

\section{Sun, Wind, and the Skin}

The devotee of sunbathing arranges to expose his skin briefly at first to the god's ardent gaze and to increase the time gradually day by day. This sensible arrangement may miscarry on a windy day due, it might be thought, to cooling of the skin deceiving him about the degree of his exposure; but it is possible that the wind has an intrinsic and additive effect. Owens et al. ${ }^{1}$ have shown that in albino mice wind aggravates acute light injury of the skin, whether light and wind are applied simultaneously or alternately. Their report offers no explanation and does not discuss the possible mechanism. While it is unsafe to assume that what happens in mice can be applied to man, or that the principle can be applied to longterm effects, including carcinogenesis (the authors promise further work on this question), it is interesting to speculate on the hypothesis that the effects of sun and wind in human skin are additive.

Sunbathers would have to allow for the influence of wind in estimating a comfortable exposure, and persons who react abnormally to light would have to be warned that wind would reduce their tolerance to sunshine. In both cases advice should stress that the wind and sun exposure could be simultaneous or consecutive. The effects of long-term exposure are, perhaps, more important. The skin never forgets an injury (putting it into the same category, according to "Saki," as women and elephants). The eventual condition of the skin results from a summation of all the injuries it has received. The fair-skinned individual who burns and freckles in the sun, and who lives in the tropics at his peril because of the risk of multiple skin cancers, would have to realize that he must protect himself habitually from wind as well as from sunshine, and in particular that he should avoid situations where both may be met in an extreme form, such as on the sea. Though this is no more than an hypothesis it makes some clinical sense, because patients with light-sensitive skins do indeed sometimes notice that wind as well as light has a bad effect on them.

1 Owens, D. W., et al., Archives of Dermatology, 1974, 109, 200. 